\title{
ESTUDO EPIDEMIOLÓGICO DAS AEROMONAS SPP., ATRAVÉS DE REP E ERIC-PCR, EM ABATEDOURO BOVINO
}

\author{
T.M. Martineli, O.D. Rossi Junior, N.D. Cereser, B.A. Kamimura, \\ M.V. Cardozo, P.C. Melo, N.M. Nespolo
}

Universidade Estadual Paulista, Faculdade de Ciências Agrárias e Veterinárias, Departamento de Medicina Veterinária Preventiva e Reprodução Animal. Via de Acesso Prof. Paulo Donato Castellane s/nº, CEP 14884900, Jaboticabal, SP, Brasil. E-mail: thaismartineli@yahoo.com

\section{RESUMO}

O gênero Aeromonas compreende espécies consideradas importantes patógenos para os seres humanos, sendo que a principal ação patogênica delas corresponde às gastroenterites. Tendo em vista sua importância como patógeno de origem alimentar, a ocorrência de Aeromonas spp. foi estudada em carcaças bovinas e ambiente do abatedouro em uma indústria do Estado de São Paulo, com o intuito de definir a possível origem comum dessas bactérias no ambiente do frigorífico através de métodos moleculares. Foram colhidas 15 amostras de 19 pontos, totalizando 285 unidades. As amostras foram colhidas dos seguintes pontos: pele seca e úmida, superfície muscular das carcaças durante a toalete e das carcaças resfriadas, mãos dos funcionários antes e durante o trabalho na sala de abate e câmara de resfriamento, facas, parede e piso da câmara de resfriamento, água (clorada, não clorada e residuária da lavagem das carcaças), carne, conteúdo intestinal e ambiente da sala de abate. Foi realizada a caracterização do gênero e os isolados foram analisados pelas técnicas de REP (Repetitive Extragenic Palindromic) e ERIC (Enterobacterial Repetitive Intergenic Consensus)-PCR. Foi encontrada similaridade $\geq 99 \%$ somente entre um isolado de superfície muscular de uma carcaça resfriada com um isolado de mão. As técnicas moleculares não possibilitaram a identificação precisa da origem das bactérias na indústria, mas possibilitaram inferir que os manipuladores podem atuar como disseminadores delas no ambiente de abate.

PALAVRAS-CHAVE: Aeromonas spp., epidemiologia molecular, abate bovino.

\section{ABSTRACT}

EPIDEMIOLOGICALSTUDY OF AEROMONASSPP.USING REP AND ERIC-PCR IN BOVINE ABATTOIR. The genus Aeromonas comprises important human pathogens and the gastroenteritises are the most common infections attributed to these microorganisms. Considering their importance as foodborne pathogens, the occurrence of Aeromonas spp. was studied on bovine carcasses and in the environment of an abattoir in State of São Paulo, Brazil, with the aim of defining the possible origin of these bacteria in the abattoir environment using molecular methods. Fifteen samples from 19 points were collected, totaling 285 units. The collecting points were: dry and wet skin, muscle surface of the carcasses during trimming process and refrigerated carcasses, operatives' hands from the slaughter room before and during the work and from refrigerated rooms, knives, wall and floor from refrigerated room, water (chlorinated, nonchlorinated and from carcass washing), meat, intestinal content and slaughter room environment. Characterization of the genus was performed and the isolates were analyzed with REP (Repetitive Extragenic Palindromic) and ERIC-PCR (Enterobacterial Repetitive Intergenic Consensus PCR) techniques. A similarity of $\geq 99 \%$ was found only between one isolate from the muscle surface of one refrigerated carcass with one isolate from a hand. The molecular techniques did not enable the precise identification of the bacteria's origin within the industry, but they permitted the inference that the operatives can spread Aeromonas in the slaughter environment.

KEY WORDS: Aeromonas spp., molecular epidemiology, bovine slaughter.

\section{INTRODUÇÃO}

Dentre os micro-organismos responsáveis pela deterioração da carne incluem-se as bactérias do gênero Aeromonas que também são consideradas importantes micro-organismos patogênicos para animais homeotermose pecilotermos. Trabalhos recentes têm enfatizado seu surgimento como patógenos 
primários relacionados a uma grande variedade de infecções locais e sistêmicas, mesmo em indivíduos imunologicamente competentes (GRAEVENITZ, 2007; DWIVEDi et al., 2008).

As Aeromonas spp. estão associadas aos ambientes aquáticos e são reconhecidas como patogênicas para peixes desde 1894 (KIRKAN et al., 2003). Essas bactérias consistem em micro-organismos oxidase e catalase positivos, anaeróbios facultativos, geralmente móveis devido à presença de flagelo polar, Gram negativas, fermentadoras de glicose. Apesar da maioria dos isolados de alimentos ser mesófilas, muitas podem se multiplicar sob temperatura de refrigeração (KIROV, 1997; DASKALOV, 2006).

O gênero Aeromonas foi inicialmente incluído na família Vibrionaceae a qual também pertencem os gêneros Vibrio, Photobacterium e Plesiomonas. Subsequentes investigações filogenéticas indicaram que as Aeromonas spp. não estão estreitamente relacionadas aos vibrios, mas, ao contrário, formam uma unidade no subgrupo $\gamma-3$ da classe Proteobacteria (Аввотт et al., 2003). Oficialmente, as Aeromonas spp. estão classificadas dentro da família Aeromonadaceae (JosePH; CARNAHAN, 2000).

Aeromonas spp. podem ser encontradas no solo, água doce e salgada, água clorada e fezes de animais (SZCZUKA; KASNOWSKI, 2004). Consequentemente, existe a possibilidade dessas bactérias adentrarem no ambiente industrial e contaminarem os equipamentos e a carne.

Alguns trabalhos já demonstraram a presença de Aeromonas spp. em carne e produtos cárneos, mas com dificuldades em estabelecer a sua real origem ou fonte de contaminação dentre as diferentes fases do abate (GIll; ReICHel, 1989; Hudson et al., 1994; Rossi Junior et al., 2006). Dúvidas, estas, que podem ser dirimidas com a utilização de estudos envolvendo epidemiologia molecular (SZCZUKA; KASNOWSKI, 2004; TACÃO et al., 2005).

Baseando-se na importância do surgimento das Aeromonas spp. como patógenos emergentes, na importância da carne bovina e seus produtos na alimentação da população, no pequeno número de trabalhos científicos referentes ao gênero Aeromonas no Brasil, principalmente em relação à sua detecção e caracterização na indústria da carne bovina, idealizouse o presente estudo, tendo como objetivo descobrir, de forma segura, a(s) fonte(s) de origem das bactérias do gênero Aeromonas para o ambiente industrial.

\section{MATERIAL E MÉTODOS}

\section{Amostragem}

O trabalho foi realizado em um matadourofrigorífico situado no interior do Estado de São Paulo cujos produtos são destinados ao comércio nacional e internacional. Foram estudados pontos do fluxograma de abate bovino que poderiam atuar como veículo de transmissão das Aeromonas spp. à carne ou pontos de disseminação do micro-organismo na indústria, particularmente no processo de abate. As amostras foram colhidas em dias normais de trabalho e foram obtidas em quatro visitas ao estabelecimento, sendo que cada visita correspondeu a três dias de colheita. Foram colhidas amostras em 19 pontos na linha de abate bovino, compreendendo desde a chegada dos animais para abate (pele seca) até a carne pronta para comercialização. Assim, em um primeiro dia foi amostrada a pele. No segundo, após os animais terem sido submetidos ao descanso, jejum e dieta e estarem preparados para o abate, foi amostrada a superfície da pele úmida das regiões dianteira e traseira e, no transcorrer do abate, foram amostrados os seguintes pontos: superfície muscular das regiões dianteira e traseira durante a fase de toalete, superfície de mãos de manipuladores (antes do início e durante as atividades) e superfície de facas na sala de matança, água tratada de abastecimento e água residuária da lavagem das carcaças - colhida em frascos de vidro estéreis, em seguida à lavagem das meias carcaças quando o excesso dessa água escorre ao longo das faces externa e interna. Além disso, no segundo dia, colhiam-se amostras do ambiente da sala de abate expondo-se por 15 minutos placas de Petri contendo os meios seletivos específicos para o gênero em estudo (ágar dextrina-ampicilina e ágar vermelho de fenolamido-ampicilina) - e conteúdo intestinal, na seção de bucharia e triparia, no momento da abertura do aparelho digestivo para a lavageme preparação destes órgãos. No terceiro dia foram colhidas amostras de superfície muscular das regiões dianteira e traseira da carcaça na câmara de resfriamento, superfície das mãos dos manipuladores da câmara de resfriamento durante suas atividades, da parede, piso e ralo da própria câmara e carne pronta para comercialização obtida na sala de desossa. Analisou-se também a água sem tratamento (não clorada) proveniente de poço artesiano do próprio estabelecimento. De cada um dos pontos descritos foram analisadas 15 amostras, totalizando 285 unidades. Asamostras deágua tratada e sem tratamento foram colhidas em frascos de vidro esterilizados contendo $0,4 \mathrm{~mL}$ de tiossulfato de sódio em solução a $10 \%$, em quantidade aproximada de $400 \mathrm{~mL}$. As amostras de superfície de pele, músculos, parede, piso e ralo foram colhidas através de suabes esterilizados, em uma área de $100 \mathrm{~cm}^{2}$ delimitada por um gabarito de aço inoxidável estéril, que foram colocados em tubos de ensaio contendo quatro mililitros de água peptonada a 0,1\%. Para a colheita de material das facas e mãos, foi utilizado um suabe para cada amostra, sendo colhido de toda a superfície da lâmina da faca e espaços interdigitais e palma das 
mãos (AMERICAN...,2001). Após a colheita, as amostras foram acondicionadas em caixa isotérmica contendo gelo reciclável e encaminhadas ao Departamento de Medicina Veterinária Preventiva da Faculdade de Ciências Agrárias e Veterinárias, Campus de Jaboticabal, Unesp, para a realização das análises.

\section{Análise microbiológica}

Foi realizado o enriquecimento seletivo em caldo tripticase-soja (TSB) adicionado de ampicilina (30 $\mathrm{mg} / \mathrm{L}$ ), seguido de plaqueamento em ágar vermelho de fenol-amido (Palumbo et al., 1985) e ágar dextrina (HAVElAar; VonK, 1988) adicionados de ampicilina ( $10 \mathrm{mg} / \mathrm{L}$ ) e incubação a $28^{\circ} \mathrm{C}$ por $24 \mathrm{~h}$. Destes meios, foram selecionadas entre seis e oito colônias sugestivas - amarelas e com halo devido à hidrólise do carboidrato do meio que, após serem caracterizadas como bastonetes Gram negativos, foram cultivadas em ágar tríplice-açúcar-ferro (TSI) (SAAD et al., 1995) e submetidas às provas da motilidade, oxidase, catalase e resistência ao agente vibriostático $\mathrm{O} / 129$ (fosfato de 2,4-diamino-6,7-diisopropylpteridine) para determinação do gênero. Para esta caracterização, Aeromonas spp. foram isoladas de 38 amostras que forneceram 253 colônias (isolados). Também foram incluídos 14 isolados obtidos de cinco amostras de ambiente não submetidas ao enriquecimento seletivo, pois foram obtidas da exposição direta das placas no ambiente de abate. Para a realização dos testes moleculares foram selecionados e analisados 62 isolados abrangendo todos os locais amostrados.

\section{Extração do DNA bacteriano}

O DNA genômico foi extraído por meio da utilização do kit GE Healthcare illustra ${ }^{\mathrm{TM}}$ bacteria genomicPrep Mini spin conforme especificações do fabricante. A qualidade e quantidade do DNA foram determinadas espectrofotometricamente a 260 e $280 \mathrm{~nm}$.

\section{Análise molecular}

As análises REPeERIC-PCR foram desenvolvidas conforme VerSALOVIC et al. (1991) e com alteração no volume total da reação.

Cada $20 \mu \mathrm{L}$ de reação de PCR continha 50 pmol de cada um dos 2 primers opostos, 100 ng de DNA, $1,25 \mathrm{mM}$ de cada um dos 4 dNTPs, $2 \mathrm{U}$ de Taq polimerase (Invitrogen, USA ${ }^{\circledR}$ ) em tampão (buffer) com $10 \%$ DMSO [v/v]. As amplificações do PCR foram realizadas em um termociclador Eppendor ${ }^{\circledast}$ com uma desnaturação inicial $\left(95^{\circ} \mathrm{C}, 7 \mathrm{~min}\right)$ seguida de 30 ciclos de desnaturação $\left(9^{\circ} \mathrm{C}, 30 \mathrm{seg}\right)$, anelamento (REP: $40^{\circ} \mathrm{C}, 1 \mathrm{~min}$; ERIC: $52^{\circ} \mathrm{C}, 1 \mathrm{~min}$ ) e extensão $\left(65^{\circ}\right.$ C, $8 \mathrm{~min})$, com uma extensão final $\left(65^{\circ} \mathrm{C}, 16 \mathrm{~min}\right)$. A reação de amplificação foi realizada com um total de 30 ciclos para REP e ERIC.

As amostras foram mantidas a $4^{\circ} \mathrm{C}$ até a realização da eletroforese dos produtos de PCR.

Os primers utilizados para REP-PCR (VERSALOVIC et al., 1991) foram:

REP 1R-I (5' - III ICG ICG ICA TCI GGC - 3')

REP 2-I (5' - ICG ICT TAT CIG GCC TAC - 3')

Os primers utilizados para ERIC-PCR(VERSALOVIC et al., 1991) foram:

ERIC 1R (5' - ATG TAA GCT CCT GGG GAT TCA C $\left.-3^{\prime}\right)$

ERIC 2 (5' - AAG TAA GTG ACT GGG GTG AGC $\left.\mathrm{G}-3^{\prime}\right)$

\section{Eletroforese e análise filogenética}

Os produtos de amplificação foram submetidos à eletroforese por 90 minutos a 120V, em uma cuba de $27 \times 47,5 \times 8 \mathrm{~cm}$ (largura $\times$ comprimento $\times$ altura), em gel de agarose a $2 \%$. Como referência, foi utilizado um marcador de peso molecular de 1 $\mathrm{kb}$ plus (Invitrogen, $\mathrm{USA}^{\circledR}$ ). Os géis foram corados com brometo de etídeo, visualizados em um transiluminador de luz ultravioleta e documentados em um fotodocumentador modelo Gel Doc (BIO RAD).

Por meio da análise do bandeamento produzido com o uso de cada oligonucleotídeo iniciador, foi conferido o parâmetro 1 para a presença de banda e 0 para a ausência de banda, permitindo a elaboração de uma matriz binária. Essa matriz foi utilizada para a construção de um filograma pelo "software" Free Tree Win 95/98/NT (Hampl et al., 2001). A similaridade genética entre os isolados foi estimada pelo coeficiente de distância descrito por NeI (1986). Para o agrupamento dos dados da matriz filogenética foi utilizado o método da média das distâncias genéticas (UPGMA - Unwrighted Pair Group Method for Arithmetic Averages) (SNEATH; SOKAL, 1973), sendo que o filograma foi obtido com o auxílio do "software" Tree View (PAGE, 1996).

Os isolados eram considerados indistinguíveis e foram atribuídos ao mesmo tipo REP ou ERIC para o filograma derivado do algoritmo UPGMA quando indicava um índice de parentesco $\geq 99 \%$ verificado pela observação visual dos padrões de banda deDNA (HARVEY et al., 2004). Heterogeneidadena intensidade e formato das bandas não foi considerada diferença.

\section{RESULTADOS E DISCUSSÃO}

Aeromonas spp. foram isoladas de superfície da peleúmida das regiões dianteira e traseira, superfície muscular das regiões dianteira e traseira durante a fase de toalete, superfície muscular das regiões dianteira e traseira da carcaça resfriada, superfície 
das mãos dos manipuladores durante o trabalho, do piso e ralo da câmara de resfriamento, água sem tratamento (não clorada), água residuária da lavagem das carcaças, carne, conteúdo intestinal e ambiente da sala de abate. Na Tabela 1 é possível verificar a quantidade de amostras positivas para Aeromonas spp. conforme os locais amostrados.

Tabela 1 - Número de amostras de Aeromonas spp. obtidas para cada local de colheita analisado em abatedouro bovino no interior de São Paulo.

\begin{tabular}{lc}
\hline Local de colheita & $\begin{array}{c}\mathrm{N}^{\mathrm{o}} \text { de } \\
\text { amostras } \\
\text { positivas/ } \\
\text { analisadas }\end{array}$ \\
\hline Pele seca & $0 / 15$ \\
Pele úmida/dianteiro & $2 / 15$ \\
Pele úmida/traseiro & $3 / 15$ \\
Sup. musc. dianteira/toalete & $2 / 15$ \\
Sup. musc. traseira/toalete & $1 / 15$ \\
Sup. musc. dianteira/carc.resfr. & $2 / 15$ \\
Sup. musc. traseira/carc.resfr. & $1 / 15$ \\
Mãos manipul. matança/antes trabalho & $0 / 15$ \\
Mãos manipul. matança/durante trabalho & $8 / 15$ \\
Mãos manipul./câm. resfriamento & $0 / 15$ \\
Facas & $0 / 15$ \\
Parede câmara resfriamento & $0 / 15$ \\
Piso e ralo câmara resfriamento & $4 / 15$ \\
Água sem tratamento & $2 / 15$ \\
Água tratada & $0 / 15$ \\
Água residuária/lavagem carcaças & $4 / 15$ \\
Carne & $4 / 15$ \\
Conteúdo intestinal & $5 / 15$ \\
Ambiente & $5 / 15$ \\
\hline Total & $43 / 285$ \\
\hline
\end{tabular}

A presença de micro-organismos no ambiente industrial pode contaminar a carcaça diretamente pela via aerógena ou através de respingos de água que tocam o piso, paredes ou equipamentos contaminados, uma vez que jatos de água sob alta pressão são constantemente utilizados na higienização, principalmente na sala de abate. Está bem documentado que Aeromonas spp. e outros gêneros de bactérias patogênicas podem ser detectados no ambiente do frigorífico, de locais como piso e paredes, piso da sala de resfriamento, pia, serras e superfícies para manipulação das carnes. Consequentemente, a possibilidade de ocorrer contaminação cruzada é substancial (GILL; JONES, 1995; BORCH; ARINDER, 2002; Rossi Junior et al., 2006).

Ainda, as mãos dos funcionários, quando contaminadas dentro da indústria, também podem contribuir para a disseminação das Aeromonas spp. Ao pesquisar a ocorrência de Aeromonas spp. nas mãos de funcionários de frigorífico bovino, Rossi Junior et al. (2000) encontraram A. hydrophila e A. caviae, com predominância desta última, sendo ambas consideradas patogênicas.

Deve-se considerar, também, o isolamento de Aeromonas spp. no conteúdo intestinal, pois, apesar de alguns autores (STERn et al., 1987; GRAY; STICKLER, 1989) relatarem a baixa ocorrência dessas bactérias nas fezes dos animais, como pode ser comprovado no presente estudo, pode-se afirmar que, mesmo sendo de baixa ocorrência, este veículo éimportante. Consequentemente, existe risco dessas bactérias chegarem à mesa do consumidor.

A prevenção da entrada e disseminação dessas bactérias provenientes de conteúdo intestinal nas dependências de abate e de manipulação da carne, por sua vez, está relacionada aos cuidados durante a evisceração das carcaças e às medidas adotadas com a finalidade de evitar contato da pele do animal, facas e equipamentos com a superfície muscular após a esfola.

Os resultados obtidos com as técnicas de REP e ERIC revelaram uma grande diversidade genética entre as bactérias encontradas. Assim, para aumentar a probabilidade de se encontrar a provável origem e/ou disseminação da contaminação das carcaças dentro da indústria, realizou-se a comparação entre os isolados de um mesmo dia de abate que correspondiam a animais de um mesmo lote, ou seja, provenientes da mesma propriedade.

A amplificação com os oligonucleotídeos REP 1R-I/REP 2-I possibilitou a amplificação de até dez bandas de DNA, dependendo do isolado, com tamanho de aproximadamente 100 a 5000 pb; a amplificação de ERIC 1R/ERIC 2 permitiu a visualização de até 13 bandas também com o mesmo tamanho. Entretanto, apesar do maior número de bandas gerado pelo ERIC em algumas amostras, o REP possibilitou a visualização das bandas em um maior número de amostras.

No presente estudo serão comentados apenas os resultados referentes à etapa de colheita em que foi obtido um resultado que apresentasse similaridade $\geq 99 \%$ entre os isolados conforme análise pelo software "Tree View". O ponto que estaria atuando como fonte de contaminação das carcaças não foi detectado precisamente. Dentre os isolados que poderiam atuar como fonte de contaminação e/ ou disseminação - pele, mãos dos funcionários, água, conteúdo intestinal, piso e parede da câmara de resfriamento e ambiente da sala de abate - somente um isolado de mão (Ed9) compartilhou 100\% de similaridade com um de superfície muscular da carcaça resfriada (Dd7), conforme visualização na Figura 1, indicando que ambos poderiam pertencer à mesma espécie ou ao mesmo grupo bacteriano; esses dados também podem ser visualizados na Figura 
2. Tal dado possibilita inferir que, muito embora os manipuladores não estejam atuando como fonte primária de contaminação das carcaças, podem atuar como disseminadores da bactéria, uma vez que Dd7 refere-se à região dianteira da carcaça. Por sua vez, esta região consiste em um local onde os manipuladores poderiam ter tocado a carcaça no momento de movê-la naqueles locais onde não havia nória automática como a câmara de refrigeração.

Isolados de diferentes pontos de colheita também compartilharam $100 \%$ de similaridade, entretanto, correspondiam à pele úmida entre dois animais pertencentes ao mesmo lote ou entre água de lavagem da carcaça com a amostra de carne do mesmo animal. Estes resultados foram obtidos pelo REP e alguns deles corroborados com ERIC.

SzCZUKA; KAZNOWSKI (2004) trabalharam com cepas de Aeromonas spp. de amostras ambientais e colhidas de fezes humanas com gastroenterite. Seus isolados apresentaram amostras de bandas com tamanho entre 100 e $3500 \mathrm{pb}$, contudo, ambas as técnicas detectaram um número um pouco inferior de bandas, principalmente com o REP.

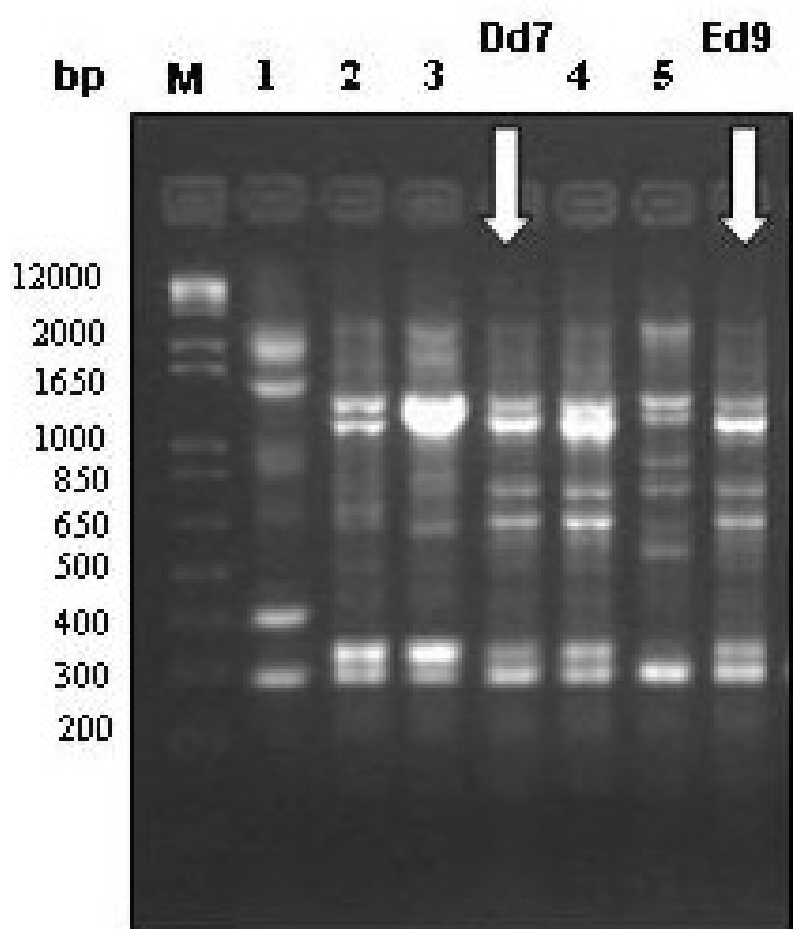

Fig. 1 - Amplificação dos isolados de Aeromonas spp. pelo conjunto de primers REP 1R-I/ REP 2-I, mostrando 100\% de similaridade entre os isolados Dd7 e Ed9. M: marcador molecular de $1 \mathrm{~Kb}$; bp: pares de bases; Dd7: isolado da superfície muscular da região dianteira da carcaça resfriada; Ed9: isolado de mão do manipulador da sala de matança durante a jornada de trabalho; 1 , 2 e 3: isolados de ambiente da sala de abate; 4 : isolado proveniente da mesma amostra de Dd7; 5: isolado de mão do manipulador da sala de matança durante a jornada de trabalho.
$10 \%$ $50 \%$

$100 \%$

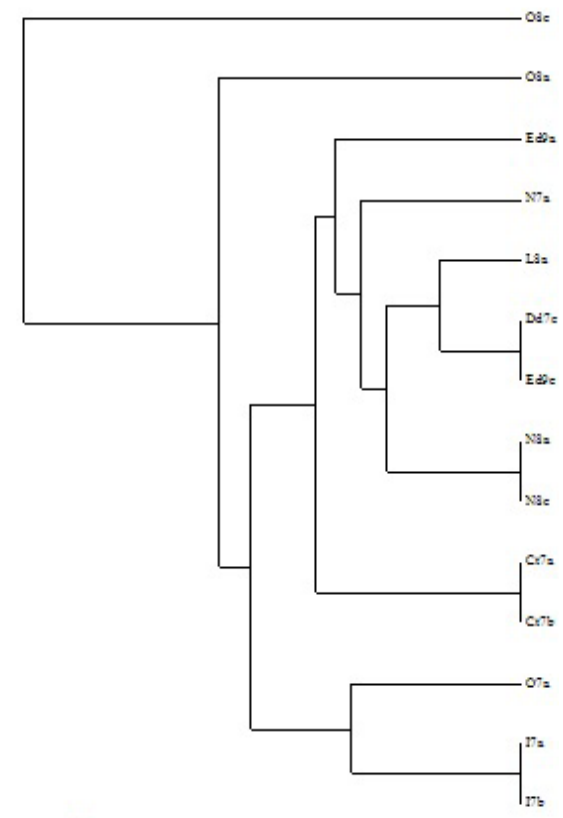

Fig. 2 - Filograma revelando o agrupamento obtido com os isolados de Aeromonas spp., baseado na amplificação das bandas de DNA pelos primers REP1R-I e REP2-I, pelo método UPGMA com bootstrap de 1000 vezes.

Muito embora a técnica de ERIC tenha produzido maior número de bandas para algumas amostras em relação ao REP, esta última possibilitou a detecção de um valor de similaridade mais alto entre os isolados. Segundo DAvin-Regli et al. (1998), a utilização de uma combinação de mais de um método molecularé importante, pois aumenta o potencial discriminatório por detectar um número mais alto de polimorfismos, aumentando, assim, a confiança no resultado.

\section{CONCLUSÕES}

Apesar dareal fontedecontaminação das Aeromonas spp. não ter sido determinada precisamente, os resultados permitiram inferir que os funcionários podem atuar como disseminadores do micro-organismo no interior da indústria.

A presença de Aeromonas spp. não só na indústria, mas principalmente na carne, indica a necessidade da melhoria das boas práticas de fabricação, pois existe a possibilidade desses micro-organismos causarem enfermidade de origem alimentar nos consumidores.

\section{AGRADECIMENTOS}

Os autores agradecem à Fundação de Amparo à Pesquisa do Estado de São Paulo (FAPESP) pelo 
suporte financeiro, à indústria onde o trabalho foi realizado pela cessão de suas instalações industriais para realização das colheitas, bem como aos funcionários da indústria pela participação e dedicação demonstradas.

\section{REFERÊNCIAS}

ABBOTT, S.L.; CHEUNG, W.K.W.; JANDA, J.M. The genus Aeromonas: biochemical characteristics, atypical reactions, and phenotypic identification schemes. Journal of Clinical Microbiology, v.41, n.6, p.2348-2357, 2003. Disponível em: <http://dx.doi.org/10.1128/ JCM.41.6.2348-2357.2003>. Acesso em: 16 jan. 2010. doi: 10.1128/JCM.41.6.2348-2357.2003.

\section{AMERICAN PUBLIC HEALTH ASSOCIATION.} Committee on Microbiological Methods for Foods. Compendium of methods for the microbiological examination of foods. 4.ed. Washington: APHA, 2001. 676p.

BORCH, E.; ARINDER, P. Bacteriological safety issues in read meat and ready-to-eat meat products, as well as control measures. Meat Science, v.62, p.381-390, 2002. Disponível em: <http://dx.doi.org/10.1016/ S0309-1740(02)00125-0>. Acesso em: 16 jan. 2010. doi: 10.1016/S0309-1740(02)00125-0.

DASKALOV, H. The importance of Aeromonas hydrophila in food safety. Food Control, v.17, p.474-483, 2006. Disponível em: <http://dx.doi.org/10.1016/j. foodcont.2005.02.009>. Acesso em: 16 jan. 2010. doi: 10.1016/j.foodcont.2005.02.009.

DAVIN-REGLI, A.; BOLLET, C.; CHAMOREY, E.; COLONNA D'ISTRIA, V.; CREMIEUX, A. A cluster of cases of infections due to Aeromonas hydrophila revealed by combined RAPD and ERIC-PCR. Journal of Medical Microbiology, v.47, p.499-504, 1998. Disponível em: <http://dx.doi.org/10.1099/00222615-47-6-499>. Acesso em: 16 jan. 2010. doi: 10.1099/00222615-476-499.

DWIVEDI, M.; MISHRA, A.; PRASAD, A.; AZIM, A.; SINGH, R.K.; BARONIA, A.K.; PRASAD, K.N.; DWIVEDI, U.N. Aeromonas caviae Septicemia in Immunocompetent Gastrointestinal Carriers. The Brazilian Journal of Infectious Diseases, v.12, n.6, p.547-548, 2008.

GILL, C.O.; JONES, T. Occurrence of Aeromonas, Listeria and Yersinia in carcass processing equipment at two slaughtering plants. Food Microbiology, v.12, n.2, p.135141, 1995. Disponível em: <http://dx.doi.org/10.1016/ S0740-0020(95)80089-1>. Acesso em: 16 jan. 2010. doi: 10.1016/S0740-0020(95)80089-1.

GILL, C.O.; REICHEL, M.P. Growth of the cold-tolerant pathogens Yersinia enterocolitica, Aeromonas hydrophila and Listeria monocytogenes on high-pH beef packaged under vacuum or carbon dioxide. Food Microbiology, v.6, p.223-230, 1989. Disponível em: <http://dx.doi. org/10.1016/S0740-0020(89)80003-6>. Acesso em: 16 jan. 2010. doi: 10.1016/S0740-0020(89)80003-6.

GRAEVENITZ, A. von. The role of Aeromonas in diarrhea: a review. Infection, v.35, n.2, p.59-64, 2007. Disponível em: <http://dx.doi.org/10.1007/s15010-007-6243-4>. Acesso em: 16 jan. 2010. doi: 10.1007/s15010-0076243-4.

GRAY, S.J; STICKLER, D. J. Some observations in the faceal carriage of mesophilic Aeromonas species in cows and pigs. Epidemiology and Infection, v.103, p.523-537, 1989.

HAMPL, V.; PAVLICEK, A.; FLEGR, J. Construction and bootstrap analysis of DNA fingerprinting-based phylogenetic trees with the freeware program Free Tree: application to trichomonad parasites. International Journal of Systematic and Evolution Microbiology, v.51, p.731-735, 2001.

HARVEY, J.; NORWOOD, D.E.; GLIMOUR, A. Comparison of repetitive element sequence-based PCR with multilocus enzyme electrophoresis and pulsed field gel electrophoresis for typing Listeria monocytogenes food isolates. Food Microbiology, v.21, p.305-312, 2004.

HAVELAAR, A.H.; VONK, M. The preparation of ampicillin dextrin agar for the enumeration of Aeromonas in water. Letters in Applied Microbiology, v.7, p.169-171, 1988 .

HUDSON, J.A.; MOTT, S.J.; PENNEY, N. Growth of Listeria monocytogenes, Aeromonas hydrophila and Yersinia enterocolitica on vacuum and saturated carbon dioxide controlled atmosphere-packaged sliced roast beef. Journal of Food Protection, v.57, p.204-208, 1994.

JOSEPH, S.W.; CARNAHAN, A.M. Update on the genus Aeromonas: despite progress, many questions about this pathogen remain unanswered. ASM News, v.66, p.218-223, 2000.

KIRKAN, S.; GÖKSOY, E.Ö.; KAYA, O. Isolation and antimicrobial susceptibility of Aeromonas salmonicida in rainbow trout (Onchorhynchus mykiss) in Turkey hatchery farms. Journal of Veterinary Medicine Series B, v.B50, p.339-342, 2003. Disponível em: <http://dx.doi.org/1 0.1046/j.1439-0450.2003.00671.x>. Acesso em: 16 jan. 2010. doi: $10.1046 /$ j.1439-0450.2003.00671.x.

KIROV, S.M. Food microbiology. fundamentals and frontiers. In: DOYLE, M.P.; BEUCHAT, L.R.; MONTVILLE, T.J. (Ed.). Aeromonas and Plesiomonas species. Washington D.C.: ASM Press, 1997. p.265-287.

NEI, M. Definition and estimation of fixation indices. Evolution, v.40, n.3, p.643-645, 1986.

PAGE, R.D.M. Tree View: an application to display phylogenetic trees on personal computers. Computational Applied Bioscience, v.12, p.357-358, 1996. 
PALUMBO, S.A.; MAXINO, F.; WILLIAMS, A.C.; BUCHANAN, R.L.; THAYER, D.W. Starch-ampicillin agar for the quantitative detection of Aeromonas hydrophila. Applied and Environmental Microbiology, v.50, p.10271030, 1985.

ROSSI JÚNIOR, O.D.; AMARAL, L.A.; NADER FILHO, A. Bactérias do gênero Aeromonas em água de matadouro bovino. Arquivo Brasileiro de Medicina Veterinária e Zootecnia, v.52, n.5, p.549-553, 2000. Disponível em: <http:/ / dx.doi.org/10.1590/S0102-09352000000500023>. Acesso em: 16 jan. 2010. doi: 10.1590/S0102-09352000000500023.

ROSSI JUNIOR, O.D.; AMARAL, L.A.; NADER FILHO, A; SCHOCKEN-ITURRINO, R.P. Bacteria of the genus Aeromonas in different locations throughout the process line of beef slaughtering. Revista Portuguesa de Ciências Veterinárias, v.101, n.557/558, p.125-129, 2006.

SAAD, S.M.I.; IARIA, S.T.; FURLANETTO, S.M.P. Motile Aeromonas spp. in retail vegetables from São Paulo, Brazil. Revista de Microbiologia, v.26, n.1, p.22-27, 1995.

SNEATH, P.H.A.; SOKAL, R.R. Numerical taxonomy the principles and practice of numerical classification. San Francisco: W. H. Freeman, 1973. 573p.
STERN, N.J.; DRAZED, E.S.; JOSEPH, S.W. Low incidence of Aeromonas spp. in livestock feces. Journal of Food Protection, v.50, p.66-69, 1987.

SZCZUKA, E.; KAZNOWSKI, A. Typing of clinical and environmental Aeromonas sp. strains by random amplified polymorphic DNA PCR, repetitive extragenic palindromic PCR, and enterobacterial repetitive intergenic consensus sequence PCR. Journal of Clinical Microbiology, v.42, n.1, p.220-228, 2004. Disponível em: <http:/ / dx.doi.org/10.1128/JCM.42.1.220-228.2004>. Acesso em: 16 jan. 2010. doi: 10.1128/JCM.42.1.220228.2004 .

TACÃO, M.; ALVES, A.; SAAVEDRA, M.J.; CORREIA, A. BOX-PCR is an adequate tool for typing Aeromonas spp. Antonie van Leeuwenhoek, v.88, p.173-179, 2005.

VERSALOVIC, J.T; KOEUTH, T; LUPSKI, J.R. Distribution of repetitive DNA sequences in eubacteria and application to fingerprinting of bacterial genomes. Nucleic Acids Research, v.19, p.6823-6831, 1991.

Recebido em 15/6/10

Aceito em 7/11/11 